\title{
Robust Adaptive Control of Dual Star Asynchronous Machine by Reference Model Based on Landau Stability Theorem
}

\author{
C. Hadji ${ }^{*}$, D. Khodja ${ }^{2}$, S. Chakroune ${ }^{1}$ \\ ${ }^{1}$ Research Laboratory of Electrical Engeneering, Technology Faculty, University of M'Sila, Algeria \\ ${ }^{2}$ Department of Electrical Engineering, Faculty of Technology, University of M'Sila, Algeria
}

Corresponding Author Email: chaabane.hadji@univ-msila.dz

https://doi.org/10.18280/ama_c.742-403

Received: 3 April 2019

Accepted: 4 August 2019

\section{Keywords:}

asynchronous machine double star, MRAC adaptive control, landau stability, RST regulator

\begin{abstract}
This article is devoted to the adaptive control with robust reference model based on a vector control applied to a dual-star asynchronous machine; this study is based on the Landau stability theorem. The adaptive control is designed for the speed loop. The identification techniques using closed-loop output error algorithm and MRAC (Model Rerferance Adaptive Control) were reviewed. All these techniques have one thing in common: they place in principle the link between robust control, closed-loop identification and adaptive control. The reference model based on the Landau stability theorem makes it possible to improve the performance of the adaptive control and maintains the robust control with respect to the parametric change of the DSIM (Doubly Star Induction Motor). The main is to ensure a minimum level of performance of the drive system that is malfunctioning. The simulation results clearly show the robustness of the proposed MRAC command against parametric variations of DSIM.
\end{abstract}

\section{INTRODUCTION}

The parameters of the machine generally depend on the operating point and vary with either the temperature (resistors) or the magnetic state of the machine (inductors), besides the load can be variable. That poses a problem of design of the control systems in the presence of uncertainties on the model of the process to be controlled in this situation. Indeed, automation engineers offer adaptive control. Thus, this command is established by sets of techniques used for the realtime automatic adjustment of the controllers of the control loops and this in order to achieve or maintain a certain level of performance when the parameters of the process to be controlled are unknown or vary in the time [1-3].

Recent developments indicate that robust adaptive control is provided by the enhancement performed in the closed loop process identification part. This leads to the calculation of a robust regulator in the presence of uncertainties on the model of the process. These uncertainties cover the variations of the parameters. There is therefore a strong interaction between robust adaptive control, closed-loop identification and robust controller calculation [3].

The rest of the article is organized as follows: Section 2 reviews the MRAC design. Then the closed-loop identification and its relation with the robust control are discussed in section 3. Section 4 presents a vector control strategy of the dual-star asynchronous machine with recalculate the RST regulator and explains the link with the MRAC adaptive control, then deduce a robust control law. Section 5 presents the simulation of the machine and testing the robustness of the regulators.

\section{ADAPTIVE CONTROL TO REFERENCE MODEL}

Adaptive Reference Model Control (MRAC) is a set of techniques for the automatic adjustment of control system controller parameters when system characteristics are unknown or variable over time. This is to eliminate the error between the desired performances (reference model) and those produced by the real system.

The interest in adaptive reference-model control over conventional control systems has some advantages:

- It provides stability and control quality for fairly large variations in the characteristics of the system to be controlled.

- It makes it possible to simplify the internal loop by simplifying the correction devices.

- It is simple to achieve. As a result, the reliability of the MRAC command is relatively high compared to conventional systems [3-4].

To overcome some of the disadvantages of the programmed gain control, (the classic adaptive method), Whitaker (in 1958) proposed a reference model control system largely developed by several specialists [5]. Such systems are composed of two closed loops; one main internal loop and the other external (Figure 1). The internal loop includes the system to be controlled and the R-S-T regulator that remains the most used because of its robustness [6]. The reference model must generate the desired instantaneous response $\omega_{\mathrm{m}}(\mathrm{k})$ of the system to be controlled. The signals from the output of the internal loop and the reference model are compared and their difference is used to design the regulator adjustment law. This adjustment is done in the sense that minimizes the difference between the system response and that of the reference model [7]. The reference model can be variable or stationary. In the latter case, the system is intended to stabilize the adjusted quantities. 


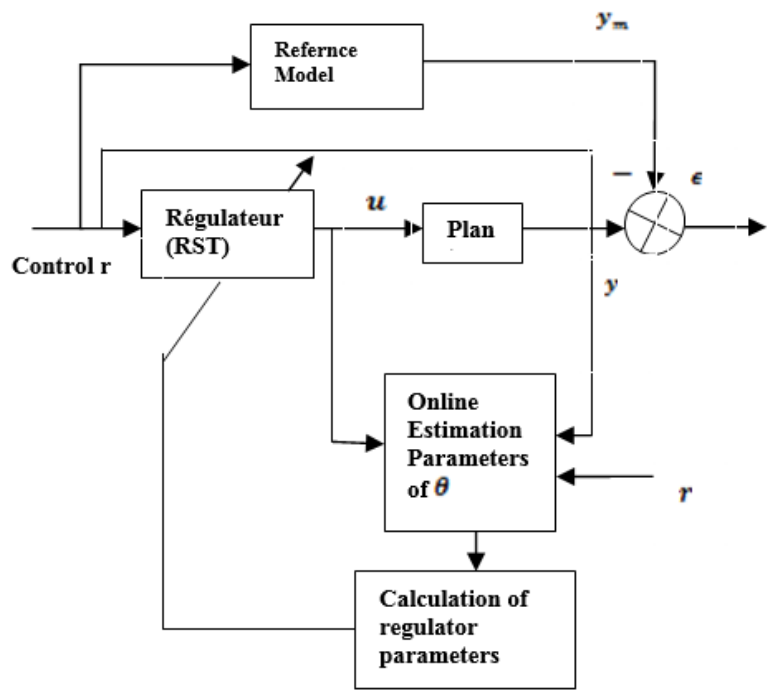

Figure 1. Scheme of Adaptive Control to Indirect Reference Model

\section{CLOSED-LOOP IDENTIFICATION AND ROBUST CONTROL}

As discussed in the introduction about the strong iterative between robust control and closed-loop identification and adaptive control, this iterative forces the automation engineer to create new identification algorithms [6-7]. New algorithms were developed in the nineties in the context of the iterative approach for closed-loop identification and recalculate the regulator. In fact, closed-loop identification can not be dissociated from the regulator and robustness considerations. The basic scheme of a digital control loop is shown in Figure 2 , the model of the machine is characterized by a transfer operator (where $\mathrm{z}^{-1}$ is the unit delay operator)

$$
\begin{gathered}
\mathrm{G}\left(\mathrm{z}^{-1}\right)=\mathrm{z}^{-\mathrm{d}} \frac{\mathrm{B}\left(\mathrm{z}^{-1}\right)}{\mathrm{A}\left(\mathrm{z}^{-1}\right)}(\text { Karimi Model }) \\
\mathrm{B}\left(\mathrm{z}^{-1}\right)=\mathrm{b}_{1} * \mathrm{z}^{-1}+\cdots \mathrm{b}_{\mathrm{n}_{\mathrm{B}}} \mathrm{z}^{-\mathrm{n}_{\mathrm{p}}} \\
=\mathrm{z}^{-1} \mathrm{~B}^{*}\left(\mathrm{z}^{-1}\right) \\
\mathrm{A}\left(\mathrm{z}^{-1}\right)=1+\mathrm{a}_{1} * \mathrm{z}^{-1}+\cdots \mathrm{a}_{\mathrm{n}_{\mathrm{A}}} \mathrm{z}^{-\mathrm{n}_{\mathrm{A}}} \\
=1+\mathrm{z}^{-1} \mathrm{~A}^{*}\left(\mathrm{z}^{-1}\right)
\end{gathered}
$$

with $\mathrm{d}$ the deley.

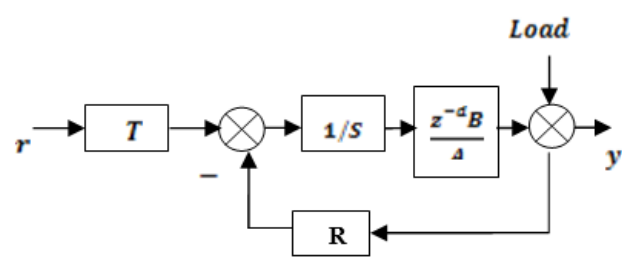

Figure 2. Closed loop system with R-S-T controller

The closed-loop system uses a digital R-S-T controller. The output of the machine (process), in closed loop, is given by:

$$
\begin{gathered}
y(t+1)=-A^{*} y(t)+B^{*} u(t-d)+A * \xi(t+1) \\
=\theta^{T} \varphi(t)+A \xi(t+1)
\end{gathered}
$$

With $\mathrm{u}(\mathrm{t})$ is the input of the process, $\mathrm{y}(\mathrm{t})$ is the output of the process, $\xi(\mathrm{t})$ is the disturbance (Load) and:

$$
\begin{aligned}
& \theta^{\mathrm{T}}=\left[\begin{array}{lllll}
\mathrm{a}_{1} & \ldots & \mathrm{a}_{\mathrm{n}_{\mathrm{A}}} \mathrm{b}_{1} & \ldots & \mathrm{b}_{\mathrm{n}_{\mathrm{b}}}
\end{array}\right] \\
& \varphi^{\mathrm{T}}=\left[-\mathrm{y}(\mathrm{t}) \ldots-\mathrm{y}\left(\mathrm{t}-\mathrm{n}_{\mathrm{A}}+1\right) \mathrm{u}(\mathrm{t}-\mathrm{d}) \ldots \mathrm{u}\left(\mathrm{t}-\mathrm{n}_{\mathrm{B}}\right.\right. \\
& +1-d)] \\
& u(t)=-\frac{R\left(z^{-1}\right)}{S\left(z^{-1}\right)} y(t)+r_{u}^{\prime}(t)
\end{aligned}
$$

With $r_{u}^{\prime}$ is the equivalent external excitation superimposed on the output of the regulator. In general:

$$
r_{u}^{\prime}=\frac{T\left(z^{-1}\right)}{S\left(z^{-1}\right)} r+r_{u}
$$

where $r$ is the reference signal and $r_{u}$ is an external signal added to the output of the regulator. In Gonzalez [7], robustness and closed-loop identification for regulator design is achieved by the sensitivity functions as follows:

The disturbance-output sensitivity function is given by:

$$
\mathrm{S}_{\mathrm{yp}}\left(\mathrm{z}^{-1}\right)=\frac{\mathrm{A}\left(\mathrm{z}^{-1}\right) \mathrm{S}\left(\mathrm{z}^{-1}\right)}{\mathrm{C}\left(\mathrm{z}^{-1}\right)}
$$

The disturbance-input sensitivity function is given by:

$$
S_{\text {up }}\left(z^{-1}\right)=-\frac{A\left(z^{-1}\right) R\left(z^{-1}\right)}{C\left(z^{-1}\right)}
$$

And $\mathrm{C}\left(\mathrm{z}^{-1}\right)$ is the characteristic polynomial of the closed loop whose roots are the poles of the closed loop:

$$
C\left(z^{-1}\right)=A\left(z^{-1}\right) S\left(z^{-1}\right)+z^{-d} B\left(z^{-1}\right) R\left(z^{-1}\right)
$$

Techniques to combine the achievement of nominal performance with the calibration of sensitivity functions have been developed and applied in practice $[4,8]$, where the fundamental purpose of closed-loop identification is to obtain a process model that leads to a better prediction of the behavior of the real closed loop. This principle is illustrated in Fig. 3 where the parametric adaptation algorithm will modify the model parameters to minimize the closed-loop output error. By following this approach consisting of algorithm families called "Closed loop output error (CLOE)" it was developed by Gang et al. [9-10], their common feature is the structure of the adjustable predicator shown in Figure 3 and given by: $\hat{y}(t+1)=\hat{\theta}^{T}(t) \varphi(t)$.

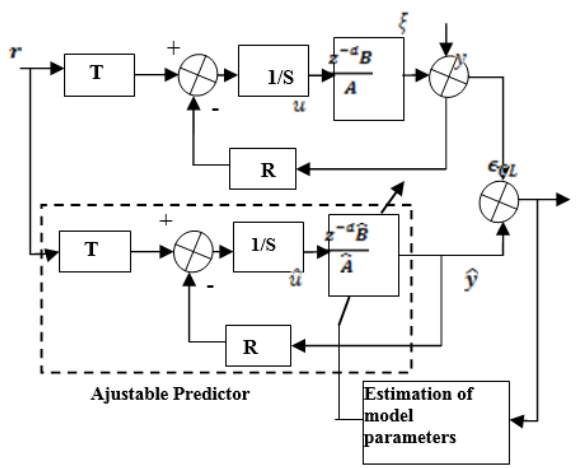

Figure 3. Identification by the method of closed loop output error 


$$
\begin{aligned}
& \hat{\theta}(t)=\left[\hat{a}_{1}(t) \ldots \hat{a}_{n_{A}}(t) \hat{b}_{1}(t) \ldots \hat{b}_{n_{B}}(t)\right], \\
& \varphi^{T}(t)=\left[-\hat{y}(t) \ldots-\hat{y}\left(t-n_{A}+1\right) \hat{u}(t-d) \ldots \hat{u}(t-\right. \\
& \left.\left.n_{B}+1-d\right)\right], \\
& \hat{y}(t)=\hat{\theta}^{T}(t) \varphi(t-1), \\
& \hat{u}(\mathrm{t})=-\frac{\mathrm{R}\left(\mathrm{z}^{-1}\right)}{\mathrm{S}\left(\mathrm{z}^{-1}\right)} \hat{\mathrm{y}}(\mathrm{t})+\mathrm{r}_{\mathrm{u}}^{\prime}(\mathrm{t}), \mathrm{r}_{\mathrm{u}}^{\prime}=\frac{\mathrm{T}\left(\mathrm{z}^{-1}\right)}{\mathrm{S}\left(\mathrm{z}^{-1}\right)} \mathrm{r}+\mathrm{r}_{\mathrm{u}} .
\end{aligned}
$$

The output error in closed loop is given by:

$$
\begin{aligned}
& \epsilon(t+1)=y(t+1)-\hat{y}(t+1) \\
& =\frac{\mathrm{s}}{\mathrm{P}}(\theta(\mathrm{t})-\hat{\theta}(\mathrm{t}+1))^{\mathrm{T}} \varphi(\mathrm{t})+\omega^{\prime}(\mathrm{t}+1),
\end{aligned}
$$

with: $\omega^{\prime}(\mathrm{t}+1)=\frac{\mathrm{AS}}{\mathrm{P}} \omega(\mathrm{t}+1)=\mathrm{S}_{\mathrm{yp}} \omega(\mathrm{t}+1)$.

According to [15], all algorithms use the following parametric adaptation algorithm:

$$
\begin{gathered}
\hat{\theta}(\mathrm{t}+1)=\hat{\theta}(\mathrm{t})+\mathrm{F}(\mathrm{t}) \varphi(\mathrm{t}) \epsilon_{\mathrm{CL}}(\mathrm{t}+1) \\
\mathrm{F}(\mathrm{t}+1)^{-1}=\lambda_{1}(\mathrm{t}) \mathrm{F}^{-1}+\lambda_{2}(\mathrm{t}) \varphi(\mathrm{t}) \varphi(\mathrm{t})^{\mathrm{T}} \\
0<\lambda_{1} \leq 1 ; 0 \leq \lambda_{2}<2 ; \\
\epsilon_{\mathrm{CL}}(\mathrm{t}+1)=\mathrm{y}(\mathrm{t}+1)-\hat{\mathrm{y}}(\mathrm{t}+1) \\
=\frac{\mathrm{y}(\mathrm{t}+1)-\hat{\mathrm{y}}(\mathrm{t}+1)}{1+\varphi^{\mathrm{T}}(\mathrm{t}) \mathrm{F}(\mathrm{t}) \varphi(\mathrm{t})}
\end{gathered}
$$

\section{ADAPTATION OF REGULATOR PARAMETERS AND CONTROL LAW}

The objective of MRAC is to obtain an adaptation mechanism that ensures the convergence of the error of the models trial to zero regardless of the initial error of the parameters. The command must be such that the output of the process that verified the equation of the model $[7,10]$ is: $\mathrm{C}_{1}\left(\mathrm{z}^{-1}\right) \mathrm{y}(\mathrm{k})=\mathrm{z}^{-1} \mathrm{D}\left(\mathrm{z}^{-1}\right) \mathrm{r}(\mathrm{k})$.

where: $\quad C_{1}\left(z^{-1}\right)=1+c_{1} z^{-1}+\cdots z^{n_{11}}, \quad D\left(z^{-1}\right)=d_{0}+$ $\mathrm{d}_{1} \mathrm{z}^{-1}+\cdots \mathrm{d}_{\mathrm{n}_{\mathrm{d}}} \mathrm{z}^{\mathrm{n}_{\mathrm{d}}}$.

In regulation we put: $r=0$.

The control must reject a disturbance with the dynamics defined by: $\mathrm{C}_{2}\left(\mathrm{z}^{-1}\right) \mathrm{y}(\mathrm{k})=0$ where: $\mathrm{C}_{2}\left(\mathrm{z}^{-1}\right)=1+\mathrm{c}_{2} \mathrm{z}^{-1}+\cdots \mathrm{c}_{2 \mathrm{n}} \mathrm{z}^{\mathrm{n}_{\mathrm{c} 2}}$.

The structure of the correction, based on the pole placement method, uses the explicit reference model described by: $\mathrm{C}_{1}\left(\mathrm{z}^{-1}\right) \mathrm{y}_{\mathrm{m}}(\mathrm{k})=\mathrm{z}^{-\mathrm{d}} \mathrm{D}\left(\mathrm{z}^{-1}\right) \mathrm{r}(\mathrm{k})$.

With $y_{m}$ and $r$ are respectively the output and the input of the reference model.

The error process of the model is defined by the equation (16) replacing $\widehat{y}$ by $y_{m}$ it gives:

$\varepsilon(\mathrm{k})=\mathrm{y}(\mathrm{k})-\mathrm{y}_{\mathrm{m}}(\mathrm{k})$ and since: $r=0$, so $\varepsilon(\mathrm{k})=\mathrm{y}(\mathrm{k})$.

The objectives of the control can be specified by: $\mathrm{C}_{2}\left(\mathrm{z}^{-1}\right) \varepsilon(\mathrm{k}+\mathrm{d})=0$.

In the case where (d>1), in order to obtain a corrector, it is necessary to rewrite the preceding equation in the more general form:

$$
\begin{aligned}
\mathrm{C}_{2}\left(\mathrm{z}^{-1}\right) \varepsilon(\mathrm{k}+\mathrm{d}) & =\mathrm{f}[\mathrm{y}(\mathrm{k}+\mathrm{d}-1) \mathrm{y}(\mathrm{k} \\
& -2) \cdot \mathrm{u}(\mathrm{k}) \mathrm{u}(\mathrm{k}-1) \ldots] \\
\mathrm{C}_{2}\left(\mathrm{z}^{-1}\right) \varepsilon(\mathrm{k}+\mathrm{d})= & \mathrm{B}\left(\mathrm{z}^{-1}\right) \mathrm{S}\left(\mathrm{z}^{-1}\right) \mathrm{u}(\mathrm{k}) \\
+ & \mathrm{R}\left(\mathrm{z}^{-1}\right) \mathrm{y}(\mathrm{k})-\mathrm{C}_{2}\left(\mathrm{z}^{-1}\right) \mathrm{y}_{\mathrm{m}}(\mathrm{k})
\end{aligned}
$$

Such a form can be obtained by using the following polynomial identity:

$$
\begin{gathered}
\mathrm{C}_{2}\left(\mathrm{z}^{-1}\right)=\mathrm{A}\left(\mathrm{z}^{-1}\right) \mathrm{S}\left(\mathrm{z}^{-1}\right)+\mathrm{z}^{-\mathrm{d}} \mathrm{R}\left(\mathrm{z}^{-1}\right) \\
\mathrm{S}\left(\mathrm{z}^{-1}\right)=1+\mathrm{s}_{1} \mathrm{z}^{-1}+\cdots \mathrm{s}_{\mathrm{ns}} \mathrm{z}^{-\mathrm{ns}} \\
\mathrm{R}\left(\mathrm{z}^{-1}\right)=\mathrm{r}_{0}+\mathrm{r}_{1} \mathrm{z}^{-1}+\cdots \mathrm{r}_{\mathrm{nr}} \mathrm{z}^{-\mathrm{nr}}
\end{gathered}
$$

This equation has a unique solution when: $n_{s}=d-1$; $n_{R}=\max \left(n_{A}-1, n_{C_{2}}-1\right)$.

The command which makes it possible to obtain the servo and regulation objective is obtained by canceling (14), is:

$$
\begin{gathered}
\mathrm{u}(\mathrm{k})= \\
\frac{1}{\mathrm{~b}_{0}}\left[\mathrm{C}_{2}\left(\mathrm{z}^{-1}\right) \mathrm{y}(\mathrm{k}+\mathrm{d})-\mathrm{R}\left(\mathrm{z}^{-1}\right) \mathrm{y}(\mathrm{k})-\mathrm{B}^{*}\left(\mathrm{z}^{-1}\right) \mathrm{u}(\mathrm{k})\right] \\
\mathrm{u}(\mathrm{k})= \\
\frac{1}{\mathrm{~B}\left(\mathrm{z}^{-1}\right) \mathrm{S}\left(\mathrm{z}^{-1}\right)}\left[\mathrm{C}_{2}\left(\mathrm{z}^{-1}\right) \mathrm{y}(\mathrm{k}+\mathrm{d})-\mathrm{R}\left(\mathrm{z}^{-1}\right) \mathrm{y}(\mathrm{k})-\right. \\
\left.\mathrm{B}^{*}\left(\mathrm{z}^{-1}\right) \mathrm{u}(\mathrm{k})\right]
\end{gathered}
$$

with:

$$
\mathrm{B}^{*}\left(\mathrm{z}^{-1}\right)=B\left(z^{-1}\right) S\left(z^{-1}\right)-b_{0} ; b_{0} \neq 0 .
$$

\section{APPLICATION OF ROBUST ADAPTIVE CONTROL BY MRAC TO ASYNCHRONOUS DUAL STATOR MACHINE}

The difficulty in controlling a dual stator asynchronous machine lies in the fact that there is a strong coupling between the input and output variables and the internal variables of the machine such as flux, torque and speed [3,11]. Conventional control methods such as torque control by frequency slip and flux by the ratio of voltage to frequency, this type of control can not ensure significant dynamic performance $[3,12]$, the development of electronics in the use of static and semiconductive converters, allowed the application of new control algorithms such as the control identical to that of the MCC.

Vector control is based on the decoupling of flux and torque in AC machines [1]. The vector control leads to high industrial performance of asynchronous drives if the rotor flow coincides with the axis (d) of the reference linked to the rotating field. And after the rotor flow orientation by: $\varphi_{\mathrm{rd}}=\varphi_{\mathrm{d}}, \varphi_{\mathrm{rq}}=0$, so:

$$
\mathrm{C}_{\mathrm{em}}=\mathrm{p} \frac{\mathrm{L}_{\mathrm{m}}}{\mathrm{L}_{\mathrm{m}}+\mathrm{L}_{\mathrm{r}}}\left(\mathrm{i}_{\mathrm{qs} 1}+\mathrm{i}_{\mathrm{qs} 2}\right) \varphi_{\mathrm{r}}
$$

The main objective according to Hellali et al. [1,13], is to produce reference voltages for the static voltage converters supplying the DSIM. Note $\mathrm{X}^{*}$ for reference quantities (torque, flux, voltages and currents). The application of the orientation of the rotor flux on the system of equations of the machine leads to [5-20-1]: $T_{r}=\frac{L_{r}}{R_{r}}, \omega_{\mathrm{s}}^{*}=\omega_{\mathrm{sr}}^{*}+\omega_{\mathrm{r}}, \omega_{s r}^{*}$

$$
\varphi_{r}=L_{m}\left(I_{s 1 d}+I_{s 2 d}\right)
$$

$$
C_{e m}^{*}=P \frac{L_{m}}{L_{m}+L_{r}} \varphi_{r}^{*}\left(I_{s q 1}+I_{s q 2}\right)
$$




$$
\begin{gathered}
\omega_{s r}^{*}=\frac{R_{r} L_{m}}{\left(L_{m}+L_{r}\right) \varphi_{r}^{*}}\left(I_{s q 1}^{*}+I_{s q 2}^{*}\right) \\
V_{s 1 d}^{*}=R_{s 1} I_{s 1 d}+L_{s 1} \frac{d}{d t} I_{d s 1}-\omega_{s}^{*}\left(L_{s 1} I_{s 1 q}+\right. \\
\left.T_{r} \varphi_{r}^{*} \omega_{s r}^{*}\right) \\
V_{s 2 d}^{*}=R_{s 2} I_{s 2 d}+L_{s 1} \frac{d}{d t} I_{d s 2} \\
-\omega_{s}^{*}\left(L_{s 1} I_{s 2 q}+T_{r} \varphi_{r}^{*} \omega_{s r}^{*}\right)
\end{gathered}
$$

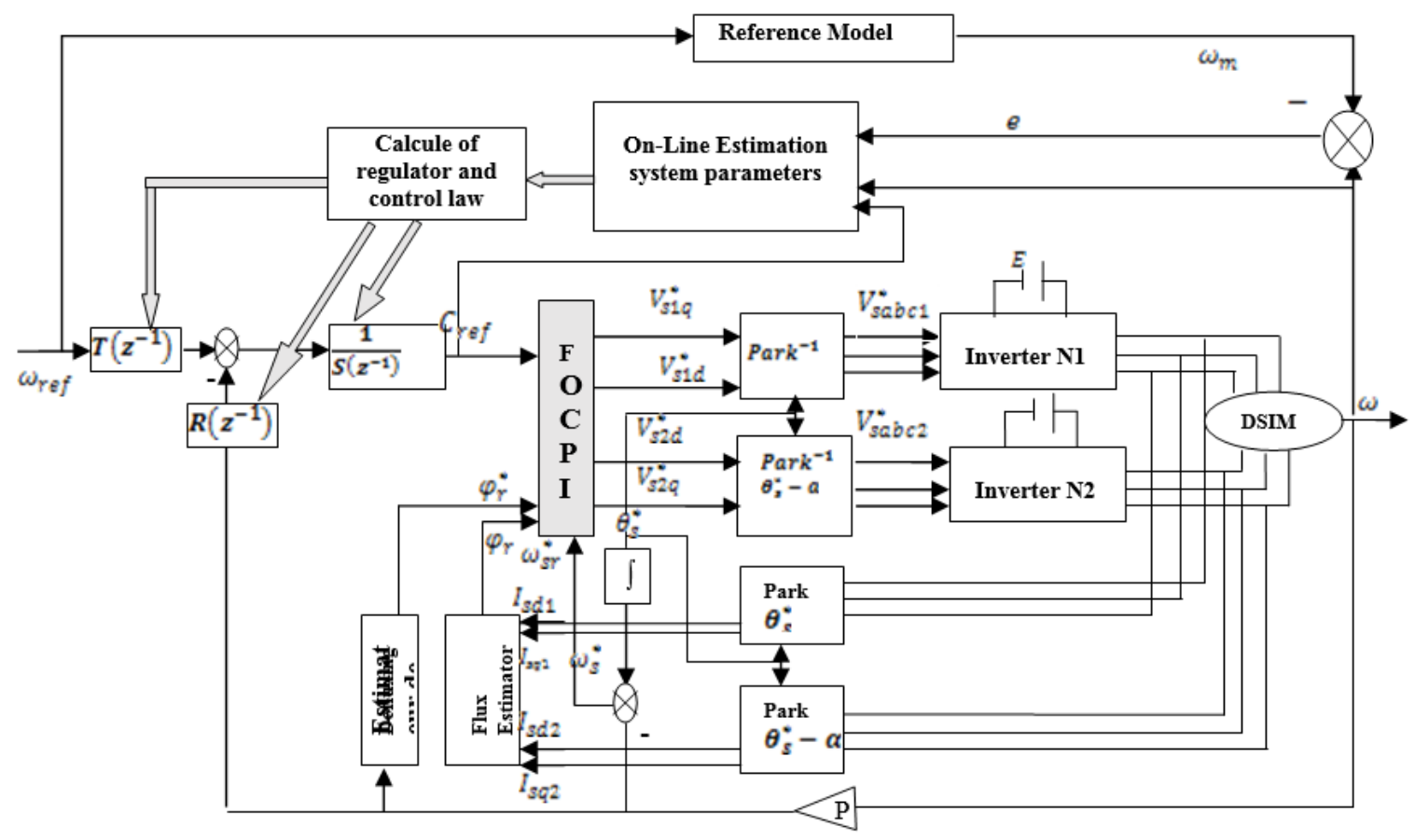

Figure 4. Scheme of the decoupled control by flux orientation applied to the DSIM

\subsection{Simulation results}

The robust regulator developed in Section 3 is evaluated in simulation, using a $4.5 \mathrm{~kW}$ double-stator asynchronous motor, whose characteristics are summarized in APPENDIX B, fed by two identical inverters. The robust MRAC regulator performance is illustrated by forcing the machine to operate under different conditions: forward and reverse speed, loaded and unloaded motor. For robust identification, the parameters of the regulators are given the following values which have proved to be suitable: $\theta^{\mathrm{T}}(0)=\left[\begin{array}{ll}0 & 0.01\end{array}\right]$, so: $\omega(\mathrm{t})=$ $\mathrm{z}^{-2} \frac{\mathrm{b}}{1+\mathrm{az} \mathrm{z}^{-1}} \mathrm{C}_{\mathrm{em}}^{*}(\mathrm{t})$.

According to the Youb et al. [13-14], to avoid the convergence toward zero of adaptation gain, we pose: $\lambda_{1}(\mathrm{k})=$ 1 and, $0<\lambda_{2}(\mathrm{k})<2$, with the initial adaptation gain is $\mathrm{F}(0)=\mathrm{I}_{2}, \mathrm{Kp}=100, \mathrm{ki}=50$. Figure. 5 shows that robust MRAC controllers have ensured a perfect speed reference tracking since the rotor speed reaches the reference speed after $t=0.45 \mathrm{~s}$ and has an overshoot of less than $1 \%$. The application of the load generates a weak attenuation of the speed during a short time $0.05 \mathrm{~s}$ then it resumes the value of speed of reference 2860 $\mathrm{rpm}$ (one applies a load of $14 \mathrm{~N} . \mathrm{m}$ to the (1:2) s), The two rotor axis component $d$ and $q$ shown in Figure 7, according to the values imposed in fully established regime and regardless of the applied load. So we say that the decoupling of FOC is perfect.

$$
\begin{aligned}
& \mathrm{V}_{\mathrm{s} 1 \mathrm{q}}^{*}=\mathrm{R}_{\mathrm{s} 1} \mathrm{I}_{\mathrm{s} 1 \mathrm{q}}+\mathrm{L}_{\mathrm{s} 1} \frac{\mathrm{d}}{\mathrm{dt}} \mathrm{I}_{\mathrm{q} 11}+\omega_{\mathrm{s}}^{*}\left(\mathrm{~L}_{\mathrm{s} 1} \mathrm{I}_{\mathrm{s} 1 \mathrm{~d}}+\varphi_{\mathrm{r}}^{*}\right) \\
& \mathrm{V}_{\mathrm{s} 2 \mathrm{q}}^{*}=\mathrm{R}_{\mathrm{s} 2} I_{s 2 q}+L_{s 2} \frac{d}{d t} I_{q s 2}+\omega_{s}^{*}\left(L_{s 2} I_{s 2 d}+\varphi_{r}^{*}\right)
\end{aligned}
$$

The current regulators have been made by the classical PI regulator in order to ensure a better robustness with respect to internal or external disturbances. Figure 4 shows the robust MRAC speed control scheme where the machine associated with two identical voltage inverters. 


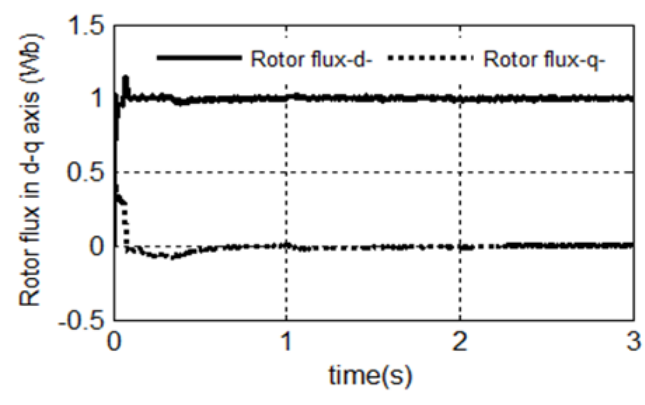

Figure 6. Output error of Speed $\left(\omega_{\mathrm{r}}-\omega_{\mathrm{m}}\right)$
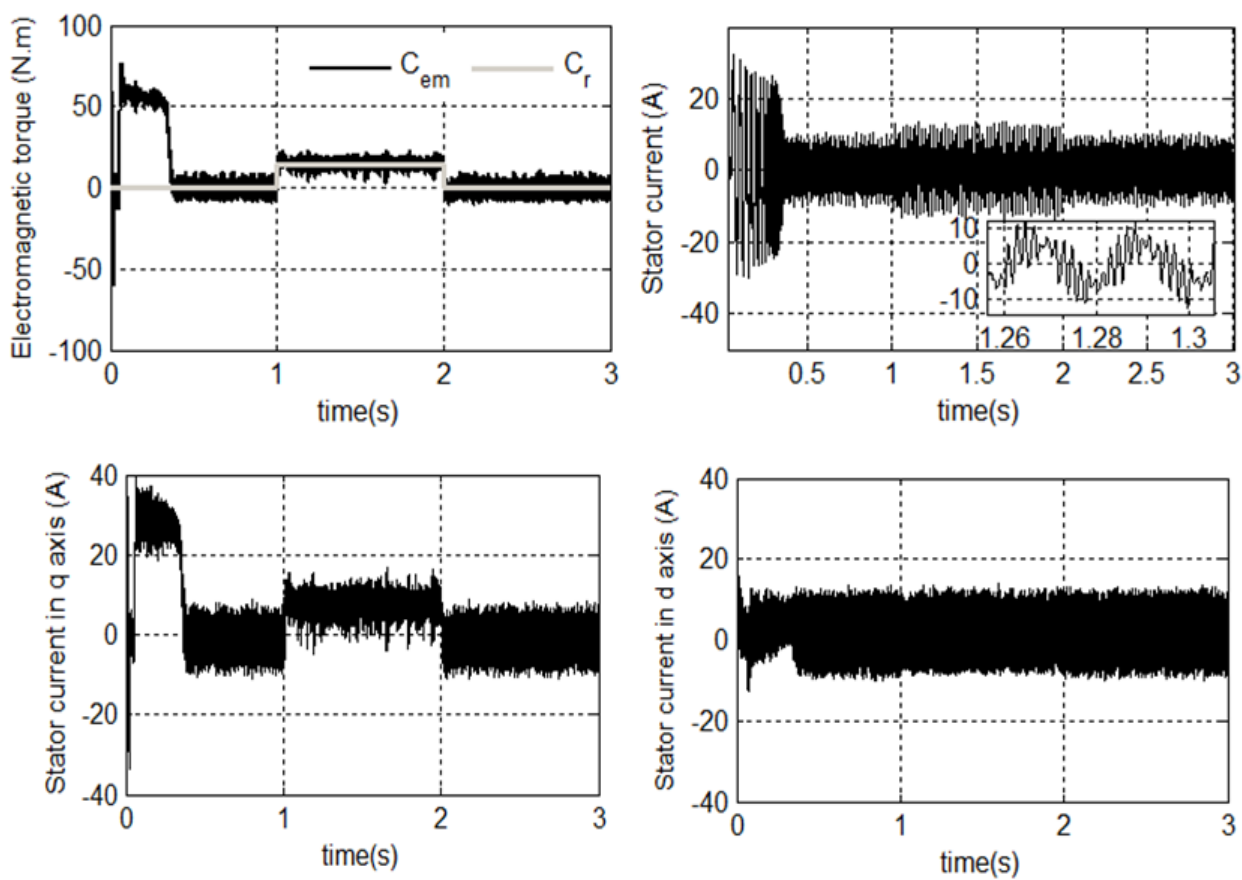

Figure 8. Presentation of electromagnetic Torque, current $\left(\mathrm{I}_{\mathrm{ds} 1} \mathrm{I}_{\mathrm{qs} 1}\right)$ and stator current

\subsection{Test de robustness}

The robustness of a robust MRAC command is made by the behavior test of the regulation with respect to the variations of the parameters of the DSIM. Since the operation of electrical machines is sensitive to variations in the rotor time constant. We will increase the rotor resistance Rr of the DSIM compared to its nominal value $\mathrm{Rr}=2 * \mathrm{Rn}$ at $\mathrm{t}=[0.8-1.5] \mathrm{s}$. With the reversal of the load speed, $\mathrm{Cr}=14 \mathrm{~N} . \mathrm{m}$ applied to $\mathrm{t}=[1-2]$.

During the transient regime and before the reversal of the speed (from $\mathrm{t}=0 \mathrm{~s}$ to $1.2 \mathrm{~s}$ ), the curves evolve in a way identical to that observed previously (Figure $8 . \mathrm{a}, \mathrm{b}, \mathrm{c}$ ), from $\mathrm{t}=1.2 \mathrm{~s}$, the speed reverses and reaches its negative setpoint after $t=0.48 \mathrm{~s}$ without any overtaking. This creates an increase in current Ias1 which is equal to the value recorded during start-up, which stabilizes after $0.48 \mathrm{~s}$, to give back to the shape of the steady state, the electromagnetic torque reaches $(-55 \mathrm{Nm})$ at moment of the inversion of the speed, which stabilizes at its negative setpoint $(-2500 \mathrm{rpm})$, the quadrature current Iqs1 progresses in a manner consistent with the electromagnetic torque, the curves of the rotor flux components observe a slight variation during the reversal of the speed. The robustness test shows the insensitivity of the speed control by the robust

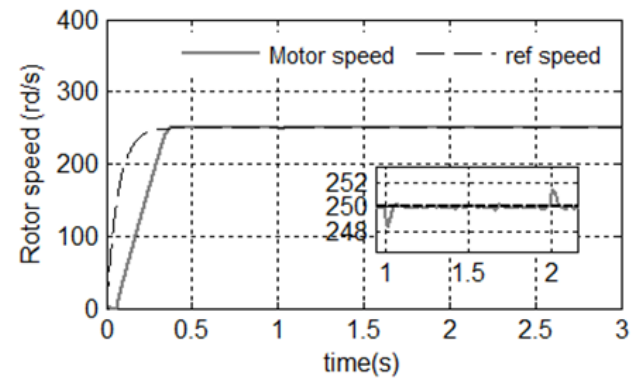

Figure 7. Rotor flux component $d$ and $q$ (phidr, phiqr) 
(a)

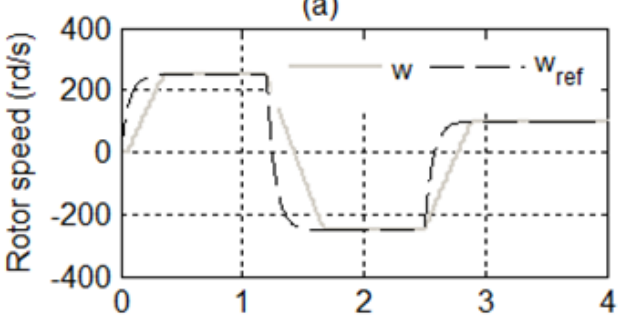

(c)

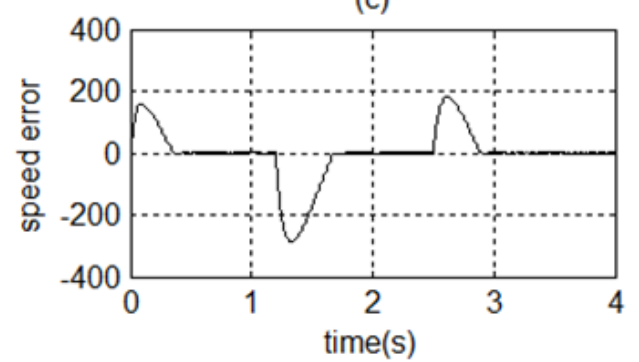

(e)

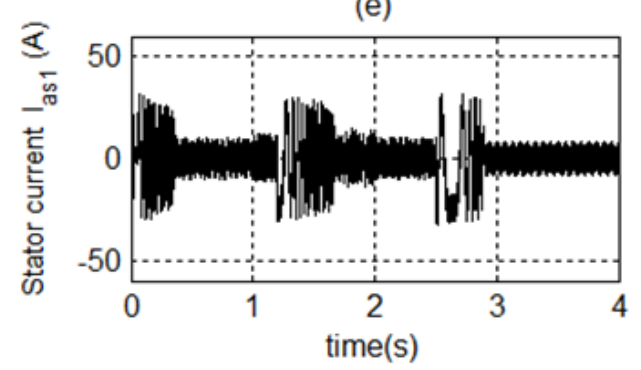

(b)

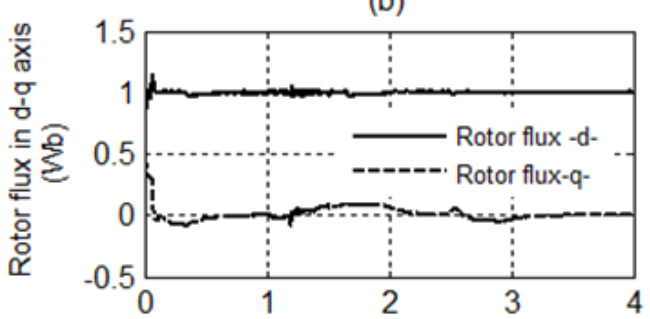

(d)

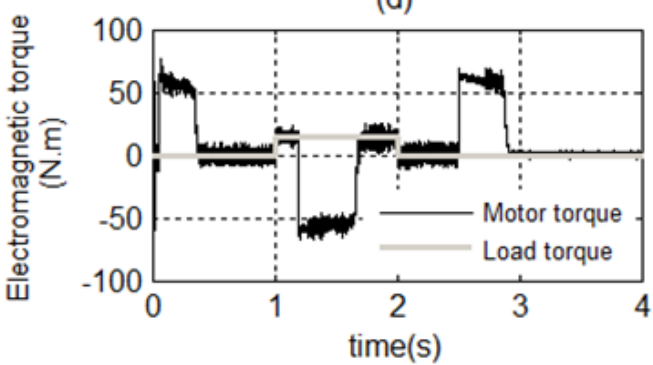

$(\mathrm{f})$

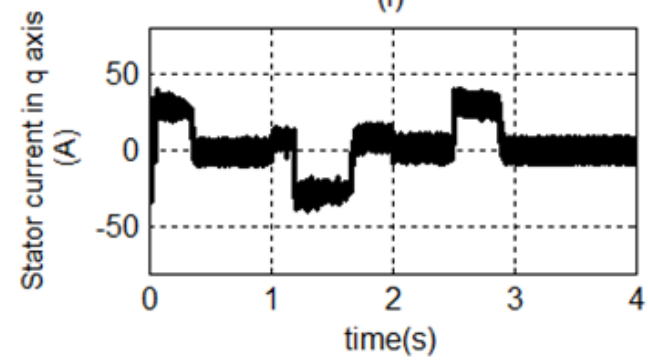

Figure 9. Simulation results of robustness tests, $\mathrm{Rr}=2 * \mathrm{R}$ at $\mathrm{t}=[0.8-1.5] \mathrm{s}$, and speed inversion in laod

\section{REFERENCES}

[1] Hellali, L., Saad, B. (2018). Speed control of doubly star induction motor (DSIM) using direct field oriented control (DFOC) based on fuzzy logic controller (FLC). AMSE Journals, Advanced in Modelling and Analysis C, 73(4):

128-136.

http://dx.doi.org/10.18280/ama_c.730402

[2] Layadi, N., Zeghlache, S., Benslimane, T., Berrabah, F. (2017). Comparative Analysis between the Rotor Flux Oriented Control and Backstepping Control of a Double Star Induction Machine (DSIM) under Open-Phase Fault. AMSE Journals, Series Advances C, 72(4): 292-311. http://dx.doi.org/10.18280/ama c.720407

[3] Hellali, R., Zeghlache, S., Benalia, L., Layadi, N. (2018). Sliding mode control based on backstepping approach for a double star induction motor (DSIM). AMSE Journals, Advanced in Modelling and Analysis C, 73(4): 150-157. http://dx.doi.org/10.18280/ama_c.730404

[4] Aissaoui, A.G., Abid, M., Abid, H., Tahour, A. (2008). Adaptive Control by Reference Model of Synchronous Machine. Review of Automatic Romanie and computers, 53(3): 295-307.

[5] Akkari, N., Chaghi, A., Abdessemed, R. (2014). Speed Control of Doubly Star Induction Motor Using Direct Torque DTC Based to on Model Reference Adaptive Control (MRAC). International Journal of Hybrid Information Technology, 7(2): 19-28. http://dx.doi.org/10.14257/ijhit.2014.7.2.03

[6] Feng, G., Lozano, G.R. (1999). Adaptative Control Système. British Library cataloguing in publication data.
[7] Gonzalez, J.L. (1988). Adaptive Control by Reference Model Discrets Systems. Report of European organization of nuclear research.

[8] Gang, T. (2003). Adaptative control Design and Analysis. Library of Congress Cataloging in Publication.

[9] Gibson, T.E. (2013). Adaptive Systems with Closed loop Reference Models Composite control and observer feedback. IFAC Proceedings, 46(11): 440-445. http://dx.doi.org/10.3182/20130703-3-FR-4038.00144

[10] Hadiouche, D. (2001). Contribution to the Study of Double Star Asynchronous Machine, Modélisation, Supply and Structure. Thesis of Doctorate of the University Henri Poincaré, Nancy, France.

[11] Hadiouche, D., Razik, H., Rezzoug, A. (2000). Study and simulation of space vector PWM control of double star induction motors. $7^{\text {th }}$ IEEE International Power Electronics Congress Technical Proceeding, 42-47. http://dx.doi.org/10.1109/CIEP.2000.891389

[12] Karimi, A., Landau, I.D. (1998). Comparison of the closed loop identification methods in terms of the bias distribution. Systems and Control Letters, 34(4): 159167. http://dx.doi.org/10.1016/S0167-6911(97)00137-0

[13] Youb, L., Belkacem, S., Naceri, F., Cernat, M., Pesquer, L.G. (2018). Design of an Adaptive Fuzzy Control System for Dual Star Induction Motor Drives. Advances in Electrical and Computer Engineering, 18(3): 36-40. http://dx.doi.org/10.4316/AECE.2018.03006

[14] Lekhchine, S., Bahi, T. (2014). Indirect rotor field oriented control based on fuzzy logic controlled double star induction machine. International Journal of 
Electrical Power and Energy Systems, 57(2): 206-211. http://dx.doi.org/10.1016/j.ijepes.2013.11.053

\section{APPENDIX A}

Nomenclature of the parameters DSIM model

\begin{tabular}{|c|c|}
\hline DSIM & Doubly Star Induction Motor \\
\hline FOC & Field Oriented Control \\
\hline IFOC & Indirect Field Oriented Control \\
\hline DFOC & Direct Field Oriented Control \\
\hline PI & Proportional and Integral \\
\hline MRAC & Model Rerferance Adaptive Control \\
\hline FLC & Fuzzy Logic Controller \\
\hline $\mathrm{V}_{\mathrm{ds}}, \mathrm{V}_{\mathrm{qs}}, \mathrm{V}_{\mathrm{dr}}, \mathrm{V}_{\mathrm{qr}}$ & $\begin{array}{l}\text { Stator and rotor voltages } \mathrm{d}-\mathrm{q} \text { axis } \\
\text { components }\end{array}$ \\
\hline $\mathrm{I}_{\mathrm{ds}}, \mathrm{I}_{\mathrm{qs}}, \mathrm{I}_{\mathrm{dr}}, \mathrm{I}_{\mathrm{qr}}$ & $\begin{array}{l}\text { Stator and rotor currents } \mathrm{d}-\mathrm{q} \text { axis } \\
\text { components }\end{array}$ \\
\hline$\varphi_{\mathrm{s}}, \varphi_{\mathrm{r}}$ & stator - rotor flux \\
\hline$\varphi_{\mathrm{d}}, \varphi_{\mathrm{q}}$ & Stator flux d- $\mathrm{q}$ axis components \\
\hline$\omega_{\mathrm{s}}, \omega_{\mathrm{r}}, \omega_{\mathrm{sr}}^{*}$ & $\begin{array}{l}\text { Stator and Rotor pulsation respectively and } \\
\text { Speed sleep Reference }\end{array}$ \\
\hline$\varphi_{\mathrm{r}}^{*}$ & Rotor flux control reference \\
\hline $\mathrm{R}_{\mathrm{s}}, \mathrm{R}_{\mathrm{r}}$ & Stator- Rotor Resistance \\
\hline $\mathrm{C}_{\mathrm{r}}$ & Load torque \\
\hline$\omega$ & Mechanical speed \\
\hline
\end{tabular}

\begin{tabular}{ll}
\hline $\mathrm{C}_{\mathrm{em}}$ & Electromagnetic torque \\
$\mathrm{L}_{\mathrm{s}}, \mathrm{L}_{\mathrm{r}}$ & Stator- and Rotor inductance respectively \\
$\mathrm{L}_{\mathrm{m}}$ & Mutual inductance \\
$\mathrm{J}$ & Total inertia \\
$\mathrm{P}$ & Number of pole pairs \\
$\mathrm{K}_{\mathrm{f}}$ & Friction coefficient \\
$\theta \mathrm{s}$ & Angle between stator and rotor flux \\
\hline
\end{tabular}

\section{APPENDIX B}

DSIM motor parameters

\begin{tabular}{l|l|l}
\hline DSIM Mechanical Power & $\mathrm{P}_{\mathrm{w}}$ & $4.5 \mathrm{Kw}$ \\
Nominal Voltage & $\mathrm{V}_{\mathrm{n}}$ & $220 \mathrm{~V}$ \\
Stators resistances & $\mathrm{R}_{\mathrm{s} 1}=\mathrm{R}_{\mathrm{s} 2}$ & $3.72 \Omega$ \\
Rotor resistance & $\mathrm{R}_{\mathrm{r}}$ & $3.72 \Omega$ \\
Stator self inductances & $\mathrm{L}_{\mathrm{s} 1}=\mathrm{L}_{\mathrm{s} 2}$ & $0.022 \mathrm{H}$ \\
Rotor self inductance & $\mathrm{L}_{\mathrm{r}}$ & $0.006 \mathrm{H}$ \\
Mutual inductance & $\mathrm{L}_{\mathrm{m}}$ & $0.3672 \mathrm{H}$ \\
Moment of inertia & $\mathrm{J}$ & $0.0662 \mathrm{Kg} \cdot \mathrm{m}^{2}$ \\
Viscous friction coefficient & $\mathrm{Kf}$ & $0.001 \mathrm{~N} \cdot \mathrm{m} / \mathrm{rd}$ \\
Nominal frequency & $\mathrm{f}$ & $50 \mathrm{~Hz}$ \\
Number of pole pairs & $\mathrm{P}$ & 1 \\
\hline
\end{tabular}

